\title{
DESEMPENHO DA MISTURA FORRAGEIRA DE AVEIA-PRETA MAIS AZEVÉM E ATRIBUTOS QUÍMICOS DO SOLO EM FUNÇÃO DA APLICAÇÃO DE ESTERCO LÍQUIDO DE SUÍNOS ${ }^{(1)}$
}

\author{
Tangriani Simioni Assmann ${ }^{(2)}$, Joice Mari Assmann ${ }^{(3)}$, Luís César \\ Cassol $^{(2)}$, Raquel Cátia Diehl ${ }^{(4)}$, Claudia Manteli ${ }^{(3)}$ \& Emanuele \\ Cavazini Magiero $^{(3)}$
}

\begin{abstract}
RESUMO
A produção de matéria seca de pastagens anuais de inverno normalmente é baixa em virtude da limitação de nutrientes disponíveis no solo, a qual pode ser corrigida com o uso de esterco líquido de suínos (ELS). Realizou-se um experimento, de maio a novembro de 2003 , visando avaliar a eficiência do esterco líquido de suínos sobre a produção de matéria seca e $\mathrm{N}$-cobertura vegetal da mistura de aveia e azevém, bem como sobre alguns atributos químicos de um Latossolo Vermelho distroférrico, nas camadas de 0-5, 5-10 e 10-20 cm. O delineamento experimental foi o de blocos ao acaso, com quatro repetições, sendo constituído por quatro tratamentos, 0, 20, $40 \mathrm{e} 80 \mathrm{~m}^{3} \mathrm{ha}^{-1}$ de ELS, aplicados aos 48 e aos 116 dias após emergência das culturas. A aplicação de $80 \mathrm{~m}^{3} \mathrm{ha}^{-1}$ resultou em aumento de $34 \%$ de matéria seca acumulada em relação à testemunha. À medida que as doses de ELS foram aplicadas, houve aumento dos teores de $\mathbf{N}$ mineral apenas na camada de solo de 0-5 cm de profundidade. A aplicação de ELS influenciou o aumento dos teores de $\mathrm{K}$ no solo apenas na camada de $0-5 \mathrm{~cm}$ de profundidade e provocou aumento no $\mathrm{pH}$ e diminuição do $\mathrm{Al}^{3+}$ trocável até $20 \mathrm{~cm}$ de profundidade. Houve aumento na quantidade de $\mathbf{N}$ na cobertura vegetal conforme as doses de ELS aplicadas, com acréscimo de $0,09 \mathrm{mg} \mathrm{dm}^{-3}$ para cada $\mathrm{m}^{3}$ de ELS aplicado.
\end{abstract}

Termos de indexação: Avena strigosa, dejeto de suíno, pastagem anual de inverno, Lolium multiflorum.

\footnotetext{
${ }^{(1)}$ Recebido para publicação em outubro de 2005 e aprovado em julho de 2007.

(2) Professor(a) Adjunto(a) da Coordenação de Agronomia da Universidade Tecnológica Federal do Paraná - UTFPR. Campus Pato Branco (PR). Caixa Postal 571, CEP 85503-390 Pato Branco (PR). E-mails: tangriani@utfpr.edu.br; cassol@utfpr.edu.br

(3) Mestranda em Agronomia da UTFPR. E-mails: assmannjoice@pop.com.br; emanuelle_c_magiero@hotmail.com

${ }^{(4)}$ Mestranda do Departamento de Solos, Universidade Estadual de Londrina - UEL. Caixa Postal 6001, CEP $86051-990$ Londrina (PR). E-mail: rachel_tche@hotmail.com
} 


\title{
SUMMARY: PERFORMANCE OF OAT AND ITALIAN RYE-GRASS MIXTURE AND SOIL CHEMICAL ATTRIBUTES AS RELATED TO LIQUID SWINE MANURE APPLICATION
}

\begin{abstract}
Dry matter production of winter annual pastures is usually low due to the limited soil nutrient availability, which can be amended by the use of liquid swine manure (LSM). This experiment, carried out from May to November 2003, aimed to evaluate the efficiency of LSM in the production and accumulation of dry matter, and N-leaf concentration of an oat/ Italian rye grass mixture, as well as the effect on some chemical attributes of an Oxisol in the soil layers $0-5,5-10$ and 10-20 cm soil layers. The experiment was arranged in a complete randomized block design with four replications. The treatments were four LSM doses $\left(0 ; 20 ; 40\right.$ and $\left.80 \mathrm{~m}^{3} \mathrm{ha}^{-1}\right)$, applied 48 and 116 days after crop emergence. The application of $80 \mathrm{~m}^{3} \mathrm{ha}^{-1}$ of SLM resulted in a $34 \%$ increase in accumulated dry matter as compared to the control treatment (no SLM application). It was observed that higher LSM doses increased mineral nitrogen concentration only in the $0-5 \mathrm{~cm}$ soil layer. LSM application increased $K$ concentration only in the $0-5 \mathrm{~cm}$ soil layer, increased the $\mathrm{pH}$ and reduced the $\mathrm{Al}^{3+}$ concentration up to 20 soil depth. LSM doses increased leaf nitrogen concentration by $0.09 \mathrm{mg} \mathrm{km}$ for each $\mathrm{m}^{3}$ of applied LSM.
\end{abstract}

Index terms: Avena strigosa, swine manure, winter annual pasture, Lolium multiflorum.

\section{INTRODUÇÃO}

A criação de suínos em confinamento é considerada uma atividade de alto potencial poluidor. Quando lançados no ambiente, em quantidade excessiva, sem adequado tratamento, os dejetos podem tornar-se agentes contaminantes da água e do solo. Dependendo de como o esterco é armazenado e, ou, manuseado, poderá também apresentar grande variação na concentração de seus componentes (Scherer et al., 1996). Por sua vez, a utilização de dejetos de suínos na agricultura pode constituir uma fonte de nutrientes para as plantas, o que pode diminuir os custos de produção.

Informações sobre o destino, transporte e aplicação dos dejetos têm sido obtidas em condições edafológicas distintas das encontradas no Brasil. É sabido, por exemplo, que a temperatura influencia grandemente as transformações do $\mathrm{N}$ no solo (Flowers \& O'Callaghan, 1983; Whitehead, 1995), um dos elementos fornecidos em maior quantidade pelos dejetos de suínos. É de fundamental importância que se avalie a potencialidade de utilização dos dejetos líquidos de suínos para condições brasileiras, em particular para culturas forrageiras, sem que essa utilização comprometa o meio ambiente.

Na maioria dos trabalhos que avaliaram o potencial fertilizante do esterco líquido de suínos (ELS), a ênfase foi dada ao $\mathrm{N}$, por ser o nutriente exigido em maior quantidade, por estar em maior concentração no esterco e por apresentar uma dinâmica complexa no solo. No entanto, além de ótima fonte de N, o ELS constitui fonte significativa de $\mathrm{P}$ e de $\mathrm{K}$.

É importante que a dose seja recomendada em função da análise química do solo, da composição do
ELS e da necessidade da cultura, a fim de contribuir para melhor aproveitamento dos nutrientes pelas plantas. Assim, haverá redução dos riscos de contaminação do solo e da água pela lixiviação de $\mathrm{N}-\mathrm{NO}_{3}{ }^{-}$no perfil do solo e pelo transporte do $\mathrm{P}$ via escoamento superficial, que são alguns dos principais problemas relatados na literatura internacional (Hatfeld, 1998).

A forma em que o $\mathrm{N}$ se encontra no dejeto e a inclusão ou não da urina junto às fezes são fatores que afetam o potencial fertilizante desse resíduo. Em média, $20 \%$ do $\mathrm{N}$ ingerido é excretado, estando $30 \%$ contido nas fezes e $70 \%$ na urina (Cheverry et al., 1986). Por outro lado, Perdomo (2001) demonstrou que a quantidade de $\mathrm{N}$ excretada é de 45 a $60 \%$, sendo 42 a $48 \%$ do $\mathrm{N}$ encontrado na urina e 9 a $11 \%$ nas fezes. Este $\mathrm{N}$ excretado e fermentado possui $50 \%$ ou mais do $\mathrm{N}$ total na forma mineral prontamente disponível às plantas (Cheverry et al., 1986). Isso faz do ELS uma ótima fonte desse nutriente, e sua eficiência de uso está relacionada ao manejo durante o armazenamento e, principalmente, por ocasião de sua distribuição na lavoura.

Espécies de plantas não leguminosas, como centeio, por exemplo, apresentam maior eficiência como recicladoras de nutrientes, reduzindo dessa forma o potencial de lixiviação de $\mathrm{N}-\mathrm{NO}_{3}{ }^{-}$em sistemas de produção de milho (Ball-Coelho \& Roy, 1997; BrandiDohrn et al., 1997). Comparando a eficiência de duas espécies como plantas recicladoras de N, McCracken et al. (1994) mostraram que o centeio, em comparação com a ervilhaca comum, foi muito mais eficiente em reduzir as perdas de $\mathrm{N}_{-} \mathrm{NO}_{3}{ }^{-}$por lixiviação. Por isso, para muitos pesquisadores, a utilização de plantas com maior potencial de reciclagem de $\mathrm{N}$ e a ocupação permanente do solo com algum cultivo representam 
alternativas eficientes em reduzir as perdas de $\mathrm{N}$ (Heinzmann, 1985; Davies et al., 1996; Ball-Coelho \& Roy, 1997; Durigon et al., 2002).

Da mesma forma, Pearson \& Ison (1997) afirmam que a recuperação do K aplicado via fertilizante é maior quando aplicado sobre pastagens constituídas por gramíneas do que quando em sistemas de produção em que o solo é arado; para o caso de gramíneas, a quantidade de K recuperado pelas plantas pode chegar a $90 \%$ da quantidade aplicada.

Na região Sul do Brasil, a pastagem de inverno mais utilizada é a mistura forrageira aveia/azevém, pela elevada produção de matéria seca e adaptabilidade ao cultivo em climas frios (Floss, 1995). Além da alta capacidade de resposta à adubação nitrogenada, atingindo $10.905 \mathrm{~kg} \mathrm{ha}^{-1}$ com aplicação de $300 \mathrm{~kg} \mathrm{ha}^{-1}$ de N (Lupatini et al., 1998), essas espécies se complementam em função de suas diferenças de ciclo, uma vez que a aveia é de ciclo precoce e o azevém tardio, o que pode prorrogar o período de utilização desta pastagem.

Este trabalho teve por objetivo avaliar o efeito da aplicação de doses crescentes de ELS na produção de matéria seca e no teor de $\mathrm{N}$ da cobertura vegetal de plantas de aveia e azevém, bem como em alguns atributos químicos do solo.

\section{MATERIAL E MÉTODOS}

O experimento foi realizado de maio a novembro de 2003, na área experimental pertencente à Universidade Tecnológica Federal do Paraná (UTFPR), situada no município de Pato Branco, região sudoeste do Estado. A região é caracterizada pelo clima Cfa (subtropical úmido), segundo a classificação de Köppen, e o solo é classificado como Latossolo Vermelho distroférrico (Embrapa, 1999). Antes da instalação do experimento, foram coletadas amostras de solo nas profundidades de $0-5,5-10$ e $10-20 \mathrm{~cm}$, para caracterização química da área experimental (Quadro 1).
A pastagem utilizada foi uma mistura forrageira de aveia-preta (Avena strigosa) cultivar IAPAR $61 \mathrm{e}$ azevém (Lolium multiflorum), implantados no dia 19 de maio de 2003, utilizando-se 80 e $20 \mathrm{~kg} \mathrm{ha}^{-1}$ de sementes, respectivamente. A adubação de base constou da aplicação de $300 \mathrm{~kg} \mathrm{ha}^{-1}$ da fórmula NPK 0-20-20. O delineamento experimental foi de blocos ao acaso, com quatro repetições. Os tratamentos foram quatro doses de $\operatorname{ELS}\left(0,20,40\right.$ e $\left.80 \mathrm{~m}^{3} \mathrm{ha}^{-1}\right)$, aplicadas aos 48 e 116 dias após emergência (DAE) das culturas. O ELS foi obtido no IAPAR (Instituto Agronômico do Paraná) e analisado quimicamente (Quadro 2).

Durante o ciclo de desenvolvimento das espécies, foram realizados três cortes para quantificação da produção de massa seca (MS), aos 68, 89 e 156 DAE. A parte aérea das plantas foi cortada rente ao solo, utilizando-se um quadrado de $0,25 \mathrm{~m}^{2}$. Após coleta, o material foi seco em estufa a $65^{\circ} \mathrm{C}$ até massa constante e pesado, para avaliação da produção de MS. Em seguida, foi moído, inicialmente, em triturador de forragens e, posteriormente, em moinho tipo Willey equipado com peneira de 40 mesh. Após o processo de digestão úmida desse material, determinou-se o teor de $\mathrm{N}$ em destilador de arraste de vapores do tipo semimicro Kjeldahl, conforme método descrito em Tedesco et al. (1995). Após cada avaliação de MS, a pastagem era cortada a $10 \mathrm{~cm}$ de altura, para simular pastejo, e a massa verde cortada era retirada das parcelas.

Após o segundo e terceiro cortes, coletaram-se amostras de solo, nas profundidades de 0-5, 5-10 e $10-20 \mathrm{~cm}$, para análise de $\mathrm{N}-\mathrm{NO}_{3}^{-}, \mathrm{N}-\mathrm{NH}_{4}{ }^{+}, \mathrm{K}$ e $\mathrm{Al}$ trocáveis, $\mathrm{MO}$ e $\mathrm{pH}$ do solo, de acordo com métodos descritos por Pavan \& Miyazawa (1996).

Os resultados das avaliações foram submetidos à análise de variância. As variáveis que se mostraram homogêneas tiveram tratamentos avaliados pelo teste F. Foram ajustadas regressões polinomiais entre os níveis de ELS (variável independente) e os das demais variáveis dependentes, buscando o modelo que melhor expressasse essa relação. Foram testados modelos linear e quadrático, e a escolha foi baseada na significância $(<5 \%)$ e no coeficiente de determinação. O programa estatístico utilizado foi o STATGRAPHICS ${ }^{\circledR}$.

Quadro 1. Atributos químicos do solo antes do início do experimento

\begin{tabular}{|c|c|c|c|c|c|c|c|c|c|}
\hline Profundidade & pH $\mathrm{CaCl}_{2}$ & MO & $\mathrm{Al}^{3+}$ & $\mathrm{Ca}^{2+}$ & $\mathrm{Mg}^{2+}$ & $\mathbf{K}^{+}$ & $\mathbf{P}$ & $\mathbf{V}$ & N-min \\
\hline $\mathrm{cm}$ & & $\mathrm{g} \mathrm{dm}^{-3}$ & 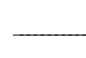 & $-\mathrm{cmc}$ & $n^{-3}$ & - & $\mathrm{mg} \mathrm{dm}^{-3}$ & $\%$ & $\mathrm{mg} \mathrm{dm}^{-3}$ \\
\hline $0,0-5,0$ & 4,5 & 43 & 0,6 & 4,2 & 2,6 & 0,3 & 10 & 42 & 91 \\
\hline $5,0-10,0$ & 4,6 & 37 & 0,4 & 4,1 & 4,2 & 0,2 & 5 & 44 & 75 \\
\hline $10,0-20,0$ & 4,6 & 34 & 0,6 & 3,5 & 0,6 & 0,1 & 3 & 40 & 66 \\
\hline
\end{tabular}

MO: matéria orgânica, V: saturação por bases, $\mathrm{N}-$ min: $\mathrm{N}$ mineral $\left(\mathrm{N}-\mathrm{NO}_{3}{ }^{-}+\mathrm{N}_{-} \mathrm{NH}_{4}^{+}\right)$. 
Quadro 2. Atributos químicos e quantidades aplicadas do esterco líquido de suínos (ELS) na mistura forrageira de aveia mais azevém

\begin{tabular}{|c|c|c|c|c|c|c|}
\hline \multirow{2}{*}{\multicolumn{2}{|c|}{ Atributo }} & & \multicolumn{4}{|c|}{ Aplicação } \\
\hline & & \multicolumn{3}{|c|}{ Primeira } & \multicolumn{2}{|c|}{ Segunda } \\
\hline \multicolumn{2}{|l|}{$\mathrm{pH}$} & \multicolumn{3}{|c|}{7,5} & \multicolumn{2}{|c|}{8,4} \\
\hline \multicolumn{2}{|c|}{ Matéria seca $\left(\mathrm{kg} \mathrm{m}^{-3}\right)$} & \multicolumn{3}{|c|}{21} & \multicolumn{2}{|c|}{41} \\
\hline \multicolumn{2}{|c|}{$\mathrm{N}^{- \text {Total }^{(1)}}\left(\mathrm{kg} \mathrm{m}^{-3}\right)$} & \multicolumn{3}{|c|}{2,1} & \multicolumn{2}{|c|}{3,1} \\
\hline & \multicolumn{6}{|c|}{ Dose ELS $\left(\mathrm{m}^{3} \mathrm{ha}^{-1}\right)$} \\
\hline & 20 & 40 & 80 & 20 & 40 & 80 \\
\hline N-Total ${ }^{(1)}$ & 42 & 84 & 170 & 62 & 124 & 248 \\
\hline P-total ${ }^{(1)}$ & 27 & 54 & 108 & 36 & 72 & 144 \\
\hline $\mathrm{K}^{(1)}$ & 35 & 70 & 140 & 45 & 90 & 180 \\
\hline
\end{tabular}

\footnotetext{
(1) Análise e cálculos em base úmida.
}

\section{RESULTADOS E DISCUSSÃO}

\section{Produção de matéria seca da mistura forrageira}

No primeiro corte, a aplicação de ELS influenciou a produção de MS da mistura forrageira de aveia/ azevém (Figura 1). A máxima eficiência técnica foi obtida com a aplicação de $64,8 \mathrm{~m}^{3} \mathrm{ha}^{-1} \mathrm{de}$ ELS, atingindo produção de $2.208 \mathrm{~kg} \mathrm{ha}^{-1}$ de MS. Trentin et al. (2002) obtiveram resultados semelhantes após dois anos consecutivos da aplicação de 20,40 e $80 \mathrm{~m}^{3} \mathrm{ha}^{-1}$ de ELS, em que observaram produções de MS de aveia-preta de $2.000,3.100$ e $4.000 \mathrm{~kg} \mathrm{ha}^{-1}$ no primeiro ano e $1.200,1.800$ e $3.300 \mathrm{~kg} \mathrm{ha}^{-1}$ no segundo, respectivamente.

No segundo corte, não houve influência das doses de ELS sobre a produtividade de MS e, em média, o acúmulo do período foi de $1.157 \mathrm{~kg} \mathrm{ha}^{-1}$ de MS (Figura 1). Provavelmente, a ausência de resposta às doses de ELS ocorreu devido ao baixo índice pluviométrico observado durante o período transcorrido entre a aplicação dos dejetos e a data de coleta da MS. Foi observado índice pluviométrico de $47,8 \mathrm{~mm}$, enquanto a média regional para o período é de $125 \mathrm{~mm}$.

Segundo Mundstock \& Bredemeier (2001), condições desfavoráveis do ambiente retardam o aparecimento ou provocam a omissão de afilhos de culturas como a aveia. Além disso, por não haver umidade no solo, as perdas por volatilização de $\mathrm{N}$ provavelmente foram maiores. Segundo Scherer et al. (1996), o N presente no ELS encontra-se até $70 \%$ na forma amoniacal $\left(\mathrm{NH}_{4}^{+}\right)$, estando, portanto,

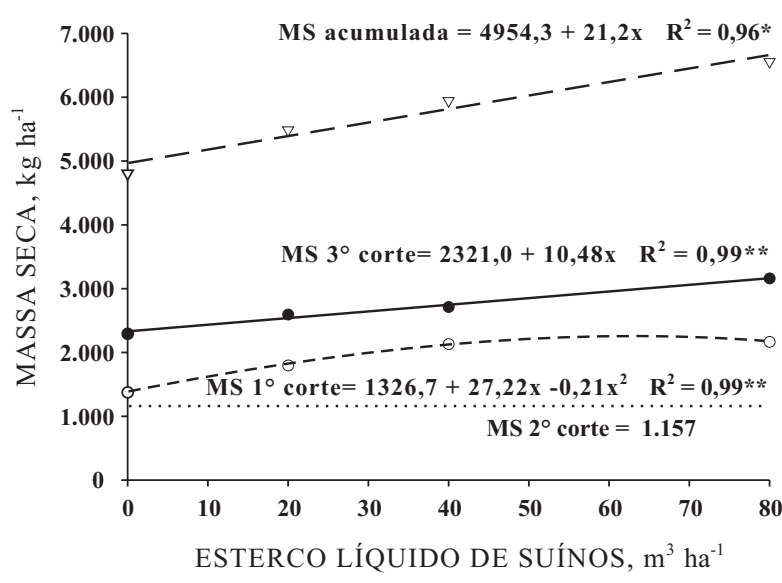

Figura 1. Produção de matéria seca da mistura forrageira de aveia mais azevém, coletada aos $68\left(1^{\circ}\right.$ corte $), 89\left(2^{\circ}\right.$ corte $)$ e $156\left(3^{\circ}\right.$ corte $)$ DAE, e massa seca acumulada em função de doses crescentes de esterco líquido de suínos.

suscetível à volatilização, que pode variar de 5 a $75 \%$ do $\mathrm{N}$ amoniacal, dependendo dos fatores climáticos, como a pluviosidade (Whitehead, 1995).

Aos 156 DAE, no terceiro corte, obteve-se aumento de $10,48 \mathrm{~kg} \mathrm{ha}^{-1}$ de MS por $\mathrm{m}^{3}$ de ELS aplicado (Figura 1), o que mostra a eficiência da reaplicação. Respostas lineares para produção de matéria seca também foram obtidas por Zebarth et al. (1996) e Almeida (2000), com o uso de doses crescentes de ELS. 
Considerando o acúmulo total de MS, a aplicação de $80 \mathrm{~m}^{3} \mathrm{ha}^{-1}$ proporcionou aumento de $34 \%$ na produção de MS da mistura forrageira de pastagem de aveia/azevém, em relação à testemunha, em um período de 156 dias (Figura 1). Oliveira et al. (1997), em experimentos realizados em pastagem perene, concluíram que a aplicação de ELS propiciou aumento na produção de MS de até $76 \%$ em relação à testemunha. Da mesma forma, Durigon et al. (2002) verificaram que, com a aplicação de 20 e $40 \mathrm{~m}^{3} \mathrm{ha}^{-1}$ de ELS em pastagem natural, o aumento da MS foi de 109 e $155 \%$, respectivamente, durante um período de quatro anos.

No caso específico deste trabalho, a menor resposta à aplicação de doses de ELS em relação a testemunha, na comparação com outros trabalhos, pode estar relacionada com as espécies testadas (aveia e azevém), que são culturas de ciclo anual, uma vez que os demais trabalhos testaram culturas perenes. Além disso, campos de pastagem natural apresentam, normalmente, baixa fertilidade e, sobretudo, baixa disponibilidade de $\mathrm{N}$ quando comparados a solos cultivados. Esses aspectos podem contribuir para maior resposta à aplicação de ELS nos ecossistemas de campos naturais.

\section{Nitrogênio na cobertura vegetal}

As doses de ELS aplicadas no solo influenciaram os teores de $\mathrm{N}$ da cobertura vegetal da mistura forrageira de aveia/azevém aos $156 \mathrm{DAE}$ (Figura 2). De acordo com a equação de regressão, para cada $\mathrm{m}^{3}$ de ELS aplicado, houve aumento de $0,09 \mathrm{~g} \mathrm{~kg}^{-1} \mathrm{de} \mathrm{N}$ na parte aérea. Basso (2003) constatou aumento na parte aérea de aveia-preta de $0,09 \mathrm{~g} \mathrm{~kg}^{-1}$ de $\mathrm{N}$ no primeiro ano e de $0,08 \mathrm{~g} \mathrm{~kg}^{-1}$ de $\mathrm{N}$ da parte aérea no segundo ano para cada $\mathrm{m}^{-3}$ de ELS aplicado, corroborando o resultado deste trabalho.

Lemaire \& Gastal (1997) indicaram que $28 \mathrm{~g} \mathrm{~kg}^{-1}$ de $\mathrm{N}$ na cobertura vegetal é o nível crítico de $\mathrm{N}$ para pastagem de inverno, considerando acúmulos de MS na faixa de $6.000 \mathrm{~kg} \mathrm{ha}^{-1}$. Como se observa na figura 1 , o acúmulo de matéria seca variou de 5.000 a $6.000 \mathrm{~kg} \mathrm{ha}^{-1}$, e a cobertura vegetal apenas apresentaria concentração de $\mathrm{N}$ superior ao nível apontado como crítico com a aplicação de aproximadamente $101 \mathrm{~m}^{3} \mathrm{ha}^{-1}$ de ELS. A aplicação de ELS não foi suficientemente eficiente para suprir a necessidade de $\mathrm{N}$ na mistura forrageira de aveia/azevém (Figura 2).

A variação de concentração do $\mathrm{N}$ na parte aérea da forrageira provocada pela aplicação de ELS (Figura 2) é semelhante à da pesquisa realizada no Sul do Brasil por Quadros \& Maraschin(1987). A concentração média de $\mathrm{N}$ na forragem foi de $27,2,25,6$ e 22,4 $\mathrm{g} \mathrm{kg}^{-1}$ de $\mathrm{N}$, para as misturas forrageiras de aveia + azevém + trevo vesiculoso, azevém + trevo vesiculoso e azevém + trevo branco + cornichão, respectivamente.

Normalmente, maiores valores de concentração de $\mathrm{N}$, na cobertura vegetal, são observados após utilização de adubos químicos nitrogenados, em relação à

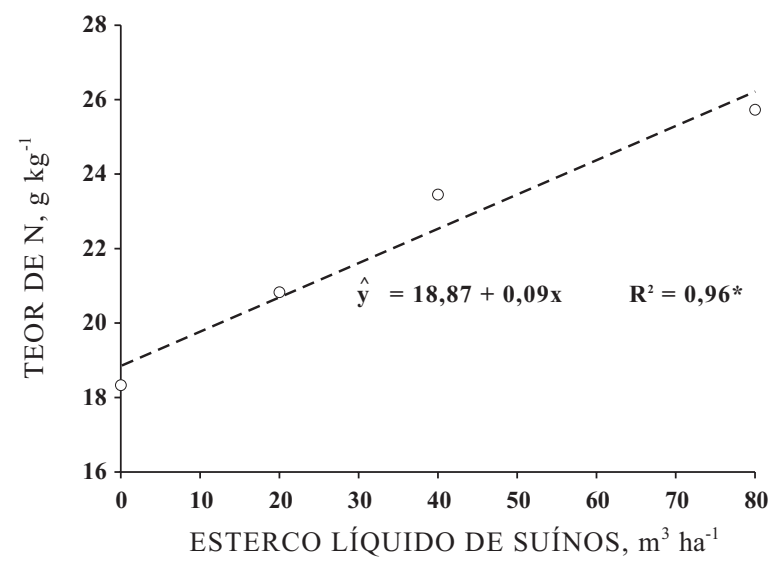

Figura 2. Teores de $\mathbf{N}$ da cobertura vegetal da mistura forrageira de aveia mais azevém, determinados aos 156 DAE ( $3^{\circ}$ corte), em função das doses de esterco líquido de suínos.

adubação orgânica. Restle et al. (2000) observaram concentrações médias de 35,4 e $36,3 \mathrm{~g} \mathrm{~kg}^{-1}$ de $\mathrm{N}$ para as fontes de $\mathrm{N}$ uréia e sulfato de amônio, respectivamente, com aplicação de $200 \mathrm{~kg} \mathrm{ha}^{-1}$ de $\mathrm{N}$ para ambos os tratamentos.

Considerando que na soma das duas aplicações, na mais alta dose de ELS $\left(80 \mathrm{~m}^{3} \mathrm{ha}^{-1}\right)$, adicionaramse $418 \mathrm{~kg} \mathrm{ha}^{-1}$ de $\mathrm{N}$, os teores de $\mathrm{N}$ observados na cobertura vegetal indicaram índice de recuperação de $41 \%$ do $\mathrm{N}$ aplicado; a quantidade total de $\mathrm{N}$ extraída pela cobertura foi de $173 \mathrm{~kg} \mathrm{ha}^{-1}$, adotando-se um valor médio de concentração de $\mathrm{N}$ na parte aérea de $26 \mathrm{~g} \mathrm{~kg}^{-1}$ durante todo o período de cultivo. Sanderson et al. (2001) encontraram taxa de $20 \%$ de recuperação de $\mathrm{N}$ quando foram aplicados dejetos de bovinos sobre uma pastagem de Panicum virgatum L.

\section{Teor de nitrogênio no solo}

Houve influência da interação entre doses de ELS e profundidade do solo sobre os teores de $\mathrm{N}$-mineral no solo (Figura 3). Aumentos nos teores de $\mathrm{N}$-mineral foram obtidos apenas na camada de solo de $0-5 \mathrm{~cm}$. A maior concentração de $\mathrm{N}$-mineral foi de $205 \mathrm{mg} \mathrm{dm}^{-3}$, tendo sido obtida com a aplicação de uma dose de ELS equivalente de $53 \mathrm{~m}^{3} \mathrm{ha}^{-1}$. Aita et al. (2006), trabalhando em um Argissolo Vermelho distrófico arênico, encontraram movimentação de $\mathrm{N}_{-} \mathrm{NO}_{3}{ }^{-}$na camada de 0-60 $\mathrm{cm}$ após aplicação de $80 \mathrm{~m}^{3} \mathrm{ha}^{-1} \mathrm{de}$ dejetos de suínos.

O resultado deste trabalho contraria a hipótese de que poderia haver perdas de $\mathrm{N}$ por lixiviação de $\mathrm{N}$ $\mathrm{NO}_{3}{ }^{-}$para camadas mais profundas do solo, uma vez que, após aplicação dos dejetos, o $\mathrm{N}$ amoniacal é rapidamente oxidado a nitrato pelas bactérias nitrificadoras (Whitehead, 1995). A redução dos teores de $\mathrm{N}$-mineral com o aumento da profundidade do solo pode ser atribuída à diminuição dos teores de MO à medida que se aprofunda no solo e ao aumento da 
atividade microbiana, motivado pelo dejeto aplicado, o qual provavelmente imobilizou o $\mathrm{N}$ adicionado via ELS, principalmente na camada de solo de $0-10 \mathrm{~cm}$ (N'Dayegamiye \& Côté, 1989). Dessa forma, ficou caracterizado o potencial fertilizante do dejeto, demonstrado por aumentos na produção de MS da pastagem de aveia/azevém (Figura 1) e nos teores de $\mathrm{N}$-mineral na camada superficial do solo (Figura 3 ). A ausência de lixiviação de $\mathrm{N}-\mathrm{NO}_{3}{ }^{-}$no perfil do solo reduz os riscos de poluição ao ambiente pelo uso de dejetos de suínos, o que sempre é uma preocupação quando essa prática é adotada.

Ao utilizar doses crescentes de $\mathrm{N}$, em área de integração lavoura-pecuária sob sistema plantio direto, Assmann (2001) também observou aumentos nos teores de $\mathrm{N}-\mathrm{NO}_{3}{ }^{-}$apenas na camada superficial do solo $(0-5 \mathrm{~cm})$. Esse autor sugere três explicações para esse fenômeno: (a) a zona de lixiviação de $\mathrm{N}_{-} \mathrm{NO}_{3}{ }^{-}$ encontra-se além dos $20 \mathrm{~cm}$ - assim, as diferenças seriam observadas em maiores profundidades; (b) a precipitação pluvial ocorrida no período de estudo, de $47,8 \mathrm{~mm}$, foi insuficiente para provocar a lixiviação do $\mathrm{N}_{-} \mathrm{NO}_{3}{ }^{-}$; e (c) parte do $\mathrm{N}$ aplicado na forma de uréia foi perdido por volatilização ou desnitrificação.

Chang \& Entz (1996), avaliando o efeito da aplicação anual de esterco de gado por um longo tempo, mostraram que as doses de esterco e a precipitação afetaram as concentrações de $\mathrm{N}_{-} \mathrm{NO}_{3}{ }^{-}$no solo; a aplicação de esterco uma, duas ou três vezes acima da recomendação $\left(60 \mathrm{~m}^{3} \mathrm{ha}^{-1} \mathrm{ano}^{-1}\right)$ resultou em acúmulo significativo de $\mathrm{N}-\mathrm{NO}_{3}{ }^{-}$na zona radicular do centeio, e mínima perda de $\mathrm{N}$ foi observada abaixo de $1,5 \mathrm{~m}$, exceto para anos com alta precipitação. Resultados semelhantes foram observados por Ingrid et al. (1997), após dois anos de aplicações consecutivas de esterco de animais. Basso et al. (2005) concluíram que as perdas de $\mathrm{N}$ e $\mathrm{P}$ por percolação são pouco

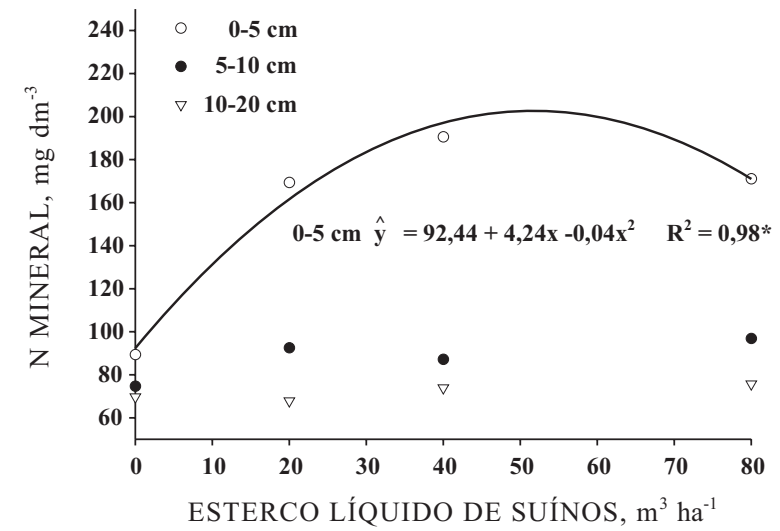

Figura 3. Teores de $\mathbf{N}$ mineral no solo, aos 156 dias após emergência da mistura forrageira de aveia mais azevém, em função de doses crescentes de esterco líquido de suínos e profundidade de amostragem. expressivas em relação às quantidades adicionadas via dejetos de suínos.

Segundo Davies et al. (1996), as plantas diminuem os teores de $\mathrm{N}$-mineral na solução do solo pela produção de MS, o que gera menor volume de água drenada. Conseqüentemente, as perdas por lixiviação profunda de $\mathrm{N}-\mathrm{NO}_{3}{ }^{-}$também diminuem. Portanto, utilizar plantas com alto poder reciclador e não deixar o solo descoberto por tempo maior que 30-40 dias são formas de reduzir as perdas de N-mineral para o lençol freático e melhorar a ciclagem de nutrientes (McCracken et al., 1994; Wiethölter, 1996).

\section{Demais atributos do solo}

Observou-se influência da interação entre doses de ELS e a profundidade do solo sobre os teores de K trocável (Figura 4). O K é o macronutriente menos abundante no ELS e seus teores dependem diretamente da quantidade de MS encontrada nesse resíduo (Scherer et al., 1996). As doses de ELS aplicadas na mistura forrageira provocaram aumentos nos teores de $\mathrm{K}$, na profundidade de $0-5 \mathrm{~cm}$ do solo, que variaram de 0,37 a $1,35 \mathrm{cmol}_{\mathrm{c}} \mathrm{dm}^{-3}$ para as doses de 0 a $80 \mathrm{~m}^{3} \mathrm{ha}^{-1}$, respectivamente. Considerando que foram feitas duas aplicações dos dejetos, a adição do ELS contribuiu com $4 \mathrm{~kg} \mathrm{~m}^{-3}$ de $\mathrm{K}$, totalizando, após a última aplicação, $320 \mathrm{~kg} \mathrm{ha}^{-1}$ de $\mathrm{K}$ para a dose mais elevada (Quadro 2). Essa quantidade de K adicionada é mais que três vezes a dose normalmente recomendada para aplicação em gramíneas.

Levando em conta os valores obtidos na análise de solo, após as duas aplicações da dose de $80 \mathrm{~m}^{3} \mathrm{ha}^{-1}$ ELS, na profundidade de $0-5 \mathrm{~cm}$, o solo apresenta $263 \mathrm{~kg} \mathrm{ha}-1$ de $\mathrm{K}$; antes das aplicações este solo tinha $51 \mathrm{~kg} \mathrm{ha}^{-1}$ deste nutiente na mesma profundidade, significando acúmulo de $212 \mathrm{~kg} \mathrm{ha}^{-1}$ de $\mathrm{K}$ nessa profundidade.

Rowe \& Fairbrother (2003) observaram que, para uma produção de $8.340 \mathrm{~kg} \mathrm{ha}^{-1}$ de azevém perene,

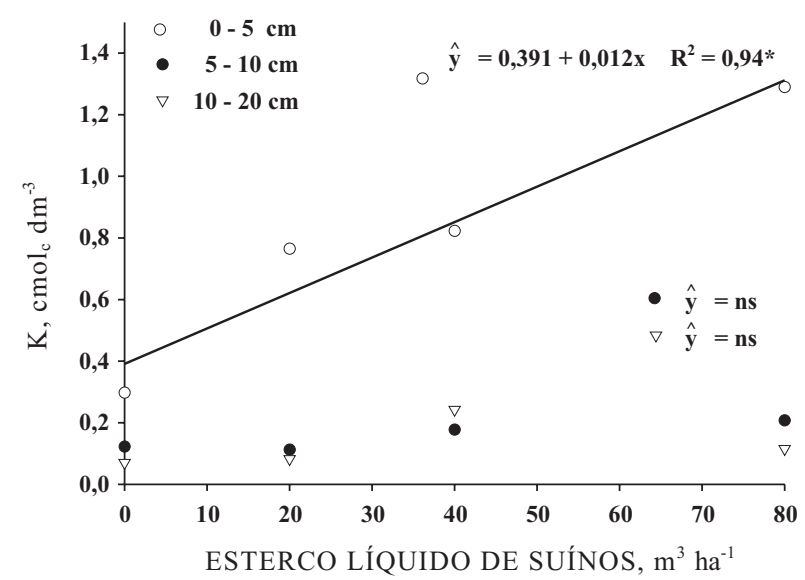

Figura 4. Teores de potássio (K), em função de doses crescentes de ELS e da profundidade de amostragem do solo. 
foram extraídos $181 \mathrm{~kg} \mathrm{ha}^{-1} \mathrm{de} \mathrm{K}$. Extrapolando essa relação para a dose mais alta de ELS aplicada neste trabalho e desconsiderando a aveia, chega-se à conclusão de que poderiam ter sido extraídos e exportados $144 \mathrm{~kg} \mathrm{ha}^{-1}$ de $\mathrm{K}$, indicando que provavelmente pouca ou nenhuma quantidade desse macronutriente foi perdida via processo de lixiviação.

Nas demais profundidades, a aplicação de ELS não provocou aumentos significativos do nutriente, apontando que, pelo menos em curto prazo, os problemas causados por provável lixiviação de nutrientes podem não ser significativos. Chateaubriand (1988), aplicando doses de 0 a $200 \mathrm{~m}^{3} \mathrm{ha}^{-1}$ de esterco de suínos na cultura do milho, por meio de irrigação por sulco, observou aumento na concentração de K disponível no solo, na profundidade de 0-20 cm, na época da floração, o mesmo não ocorrendo no período da colheita.

Diferentemente, Ceretta et al. (2003) constataram diminuição dos teores de $\mathrm{K}$ no solo com aplicação de dejetos de suínos até a profundidade de $20 \mathrm{~cm}$, o que foi justificado pela alta taxa de absorção de K pela pastagem natural e conseqüente maior exportação de $\mathrm{K}$ da área quando aplicado o ELS, uma vez que a adição de outros nutrientes na pastagem, como $\mathrm{N} \mathrm{e}$ $\mathrm{P}$, provavelmente provocou maior demanda de $\mathrm{K}$ do solo, quando comparado àquelas parcelas que não receberam adubação orgânica.

Constatou-se influência das doses de ELS sobre o teor de $\mathrm{Al}^{3+}$ trocável e o pH do solo (Figura 5). Em curto período de tempo, a aplicação de ELS reduziu o teor de $\mathrm{Al}^{3+}$ de 0,53 para $0,25 \mathrm{cmol}_{\mathrm{c}} \mathrm{dm}^{-3} \mathrm{e}$ aumentou o pH de 4,52 para 4,79, com as doses de 0 e $80 \mathrm{~m}^{3} \mathrm{ha}^{-1}$, respectivamente.

Whalen et al. (2000) constataram que a adição de esterco de cavalo fresco aumentou o $\mathrm{pH}$ do solo de 4,8 até 6,0 ; provavelmente, isso se deveu à presença de $\mathrm{CaCO}_{3}$ utilizado na dieta alimentar dos cavalos, o qual é excretado nos estercos (Eghball, 1999). De forma

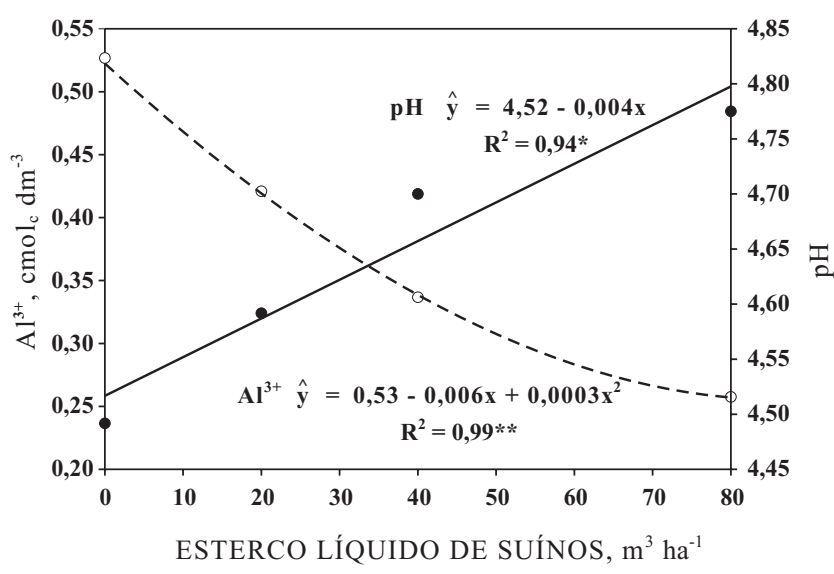

Figura 5. Teores de alumínio trocável $\left(\mathrm{Al}^{3+}\right)$ e pH do solo, em função de doses crescentes de ELS, na camada de 0-20 cm. semelhante ao calcário, o efeito do esterco animal sobre o $\mathrm{pH}$ do solo pode persistir durante muitos anos, uma vez que os compostos orgânicos liberados durante o processo de decomposição do esterco podem formar complexos com o $\mathrm{Al}$, diminuindo sua fitotoxicidade (Iyamuremye et al., 1996).

É importante ressaltar que a ação do ELS deu-se por igual na profundidade de $0-20 \mathrm{~cm}$, mostrando que, diferentemente da ação do calcário, ele pode provocar correção dos teores de Al, em profundidade.

A adição de material orgânico, seja resíduos vegetais ou animais, ao solo diminui o teor de Al trocável (Hargrove \& Thomas, 1982; Miyazawa et al., 1993), o que pode ser explicado pelo aumento do $\mathrm{pH}$ do solo, ocasionando hidrólise do $\mathrm{Al}^{3+}$, e pela complexação orgânica deste (Miyazawa et al., 1993). Essa complexação pode ser atribuída a duas reações químicas: pela formação de complexos orgânicos solúveis com os ácidos orgânicos (cítrico, tartárico, malônico, oxálico) presentes no material orgânico, que são lixiviados à camada inferior do solo, e pela formação de complexos insolúveis com as substâncias orgânicas de alto peso molecular, adsorvidas nas superfícies das partículas do solo (Miyazawa et al., 1998).

A neutralização do $\mathrm{Al}^{3+} \mathrm{e}$ o aumento do $\mathrm{pH}$ além da camada superficial foram relatados por Hue \& Amien (1989), após aplicação de esterco de animais no solo, e por Franchini et al. (1999), com extratos de resíduos vegetais. Resultados semelhantes foram obtidos por Hue \& Licudine (1999) com aplicação de esterco de aves e lodo de esgoto no solo, atribuindo-se esse efeito à presença de compostos orgânicos, que aumentam significativamente no solo com a adição de grande quantidade de carbono. Ceretta et al. (2003) verificaram diminuição do $\mathrm{Al}$ trocável até $40 \mathrm{~cm}$ de profundidade, com aumento da $\mathrm{MO}$ apenas na camada 0-5 cm, na dose de $40 \mathrm{~m}^{3} \mathrm{ha}^{-1}$ de ELS, em um Alissolo Crômico órtico típico. Neste trabalho não se constatou aumento nos teores de MO no solo.

Embora não ocorra aumento no teor de MO, devemse considerar as características intrínsecas do esterco utilizado, em que a qualidade dos compostos orgânicos pode determinar maior ou menor acúmulo de $\mathrm{MO}$ no solo. Os compostos orgânicos presentes no ELS são de fácil mineralização, oxidando em poucos dias ou semanas (Redoy et al., 1979), favorecidos pela maior atividade microbiana decorrente do esterco aplicado. No entanto, pode haver complexação do $\mathrm{Al}^{3+}$ antes que os compostos sejam oxidados pela microbiota do solo (Franchini et al., 1999).

\section{CONCLUSÕES}

1. Em um período de 156 dias, a aplicação de $80 \mathrm{~m}^{3} \mathrm{ha}^{-1}$ de ELS promoveu incremento de $34 \%$ na produção de matéria seca acumulada de aveia e azevém, quando comparada à testemunha, evidenciando o potencial fertilizante do dejeto utilizado. 
2. Apesar do aumento na produção de MS, em todas as doses aplicadas, a concentração de $\mathrm{N}$ da cobertura vegetal permaneceu em níveis inferiores ao considerado crítico.

3. A aplicação de ELS promoveu aumento nos teores de $\mathrm{N}$-mineral apenas na camada de $0-5 \mathrm{~cm}$ do solo.

4. A aplicação de esterco líquido de suínos aumentou os teores de $\mathrm{K}$ apenas na camada superficial do solo. Entretanto, o uso desse dejeto aumentou o $\mathrm{pH}$ e reduziu os teores de $\mathrm{Al}$ no solo até $20 \mathrm{~cm}$ de profundidade.

\section{LITERATURA CITADA}

AITA, C.; PORT, O. \& GIACOMINI, S.J. Dinâmica do nitrogênio no solo e produção de fitomassa por plantas de cobertura no outono/inverno com o uso de dejetos de suínos. R. Bras. Ci. Solo, 30:901-910, 2006.

ALMEIDA, A.C.R. Uso associado de esterco líquido de suínos e plantas de cobertura de solo na cultura do milho. Santa Maria, Universidade Federal de Santa Maria, 2000. 114p. (Tese de Mestrado)

ASSMANN, T.S. Rendimento de milho em área de integração lavoura-pecuária sob sistema plantio direto, em presença e ausência de trevo branco, pastejo e nitrogênio. Curitiba, Universidade Federal do Paraná, 2001. 63p. (Tese de Doutorado)

BALL-COELHO, B.R. \& ROY, C.R. Overseeding rye into corn reduces $\mathrm{NO}_{3}-$ leaching and increases yields. Can. J. Soil Sci., 77:443-451, 1997.

BASSO, C.J. Perdas de nitrogênio e fósforo com aplicação no solo de dejetos líquidos de suínos. Santa Maria, Universidade Federal de Santa Maria, 2003. 125p. (Tese de Doutorado)

BASSO, C.J.; CERETTA, C.A.; DURIGON, R.; POLETTO, N. \& GIROTTO, E. Dejetos líquido de suínos: II - perdas de nitrogênio e fósforo por percolação no solo sob plantio direto. Ci. Rural, 35:1305-1312, 2005.

BRANDI-DOHRN, F.M.; DICK, P.R.; HESS, M.; KAUFFMAN, M.S.; HEMPHILL, D.D. \& SELKER, S.J. Nitrate leaching under a cereal rye cover crop. J. Environ. Qual., 26:181188, 1997.

CERETTA, C.A.; DURIGON, R.; BASSO, C.J.; BARCELLOS, L.A.R. \& VIEIRA, F.C.B. Características químicas de solo sob aplicação de esterco líquido de suínos em pastagem natural. Pesq. Agropec. Bras., 38:729-735, 2003.

CHANG, C. \& ENTZ, T. Nitrate leaching losses under repeated cattle feedlot manure applications in Southern Alberta. J. Environ. Qual., 25:145-153, 1996.

CHATEAUBRIAND, A.D. Efeito de esterco líquido de suínos aplicados em irrigação por sulcos, na cultura do milho (Zea mays L.). Viçosa, MG, Universidade Federal de Viçosa, 1988. 61p. (Tese de Mestrado)
CHEVERRY, C.; MENETRIER, Y.; BORLOY, J. \& HEBUIT, M. Distribuição do chorume de suínos e fertilização. Tradução: Osvaldo E. Aranha. Curitiba, ACARPA, 1986. 43p.

DAVIES, D.B.; GARWOOD, T.W.D. \& ROCHAFORD, A.D.H. Factors affecting nitrate leaching from a calcareous loam in East Anglia. J. Agric. Sci., 126:75-86, 1996.

DURIGON, R.; CERETTA, C.A.; BASSO, C.J.; BARCELLOS, L.A.R. \& PAVINATO, P.S. Produção de forragem em pastagem natural com o uso de esterco líquido de suínos. R. Bras. Ci. Solo, 26:983-992, 2002.

EGHBALL, B. Liming effects of beef cattle feedlot manure or compost. Comm. Soil Sci. Plant Anal., 30:2563-2570, 1999.

EMPRESA BRASILEIRA DE PESQUISA AGROPECUÁRIA EMBRAPA. Centro Nacional de Pesquisa de Solos. Sistema brasileiro de classificação de solos. Brasília, 1999. 412p.

FLOSS, E.L. Manejo forrageiro da aveia (Avena sp.) e do azevém (Lolium sp). In: SIMPÓSIO SOBRE MANEJO DE PASTAGENS, 9., Piracicaba, 1988. Anais. Piracicaba, FEALQ, 1995. p.191-228.

FLOWERS, T.H. \& O'CALLAGHAN, O.R. Nitrification in soils incubated with pig slurry or ammonium sulphate. Soil Biol. Biochem., 13:337-342, 1983

FRANCHINI, J.C.; MIYZAWA, M.; PAVAN, M.A. \& MALAVOLTA, F. Dinâmica de íons em solo ácido lixiviado com extratos de resíduos vegetais de adubos verdes e soluções puras de ácidos orgânicos. Pesq. Agropec. Bras., 34:2267-2276, 1999 .

HARGROVE, W.L. \& THOMAS, G.W. Extraction of aluminum from aluminum-organic matter complexes. Soil Sci. Soc. Am. J., 45:151-153, 1982.

HATFIELD, J. Nutrient management \& waste handling. In: WORLD PORK SYMPOSIUM, Des Moines, 1998. Proceedings. Des Moines, 1998. p.41-48.

HEINZMANN, F.X. Resíduos culturais de inverno e assimilação de nitrogênio por culturas de verão. Pesq. Agropec. Bras., 20:1021-1030, 1985.

HUE, N.V. \& AMIEN, I. Aluminum detoxification with green manures. Comm. Soil Sci. Plant Anal., 20:1499-1511, 1989.

HUE, N.V. \& LICUDINE, D.L. Amelioration of subsoil acidity through surface application of organic manures. J. Environ. Qual., 28:623-632, 1999.

INGRID, T.K.; KJELLERUP, V. \& BENDT, J. Crop uptake leaching of ${ }^{15} \mathrm{~N}$ applied in ruminant slurry with selectively labelled faeces and urine fraction. Plant Soil, 197:233$239,1997$.

IYAMUREMYE, F.; DICK, R.O. \& BAHAM, J. Organic amendments and phosphorus dynamics: I. Phosphorus chemistry and sorption. Soil Sci., 161:426-435, 1996.

LEMAIRE, G. \& GASTAL, F. N uptake and distribution in plant canopies. In: LEMAIRE, G., ed. Diagnosis of the nitrogen status in crops. Berlin, Springer-Verlag, 1997. p.3-43.

LUPATINI, G.C.; RESTLE, J.; CERETTA, M.; MOOJEN, E.L. \& BARTZ, H.R. Avaliação da mistura de aveia-preta e azevém sob pastejo submetida a níveis de nitrogênio. I Produção e qualidade de forragem. Pesq. Agropec. Bras., 33:1939-1943, 1998. 
McCRACKEN, D.V.; SMITH, M.S.; GROVE, J.H.; MACKOWN, C.T. \& BLEVINS, R.L. Nitrate leaching as influenced by cover cropping and nitrogen source. Soil Sci. Soc. Am. J., 58:1476-1483, 1994.

MIYAZAWA, M.; PAVAN, M.A. \& CALEGARI, A. Efeito de material vegetal na acidez do solo. R. Bras. Ci. Solo, 17:411416,1993

MIYAZAWA, M.; PAVAN, M.A. \& FRANCHINI, J.C. Organic mobility of surface applied lime under no-tillage. In INTERNATIONAL MEETING OF THE INTERNATIONAL HUMIC SUBSTANCE SOCIETY, 9., Adelaide, 1998. Anais. Adelaide, International Humic Substances Society, 1998. p.66.

MUNDSTOCK, C.M. \& BREDEMEIER, C. Disponibilidade de nitrogênio e sua relação com o afilhamento e o rendimento de grãos de aveia. Ci. Rural., 32:205-211, 2001.

N'DAYEGAMIYE, A. \& CÔTÉ, D. Effect of long term pig slurry and solid cattle manure application on soil chemical and biological properties. Can. J. Soil Sci., 69:39-47, 1989.

OLIVEIRA, E.; POSTIGLIONI, S.R.; SÁ, J.P.G. \& OLIVEIRA, J.C. Efeito da adubação orgânica e mineral no rendimento de Hemarthria altissima e Cynodon nlemfuensis In: REUNIÃO ANUAL DA SOCIEDADE BRASILEIRA DE ZOOTECNIA, 34., Juiz de Fora, 1997. Anais. Juiz de Fora, Sociedade Brasileira de Zootecnia, 1997. CD-ROM.

PAVAN, M.A. \& MIYAZAWA, M. Análises químicas de solo: parâmetros para interpretação. Londrina, IAPAR, 1996. 48p. (Circular Técnica, 91)

PEARSON, C.J. \& ISON, R.L. Agronomy of grassland systems. Cambridge, Cambridge University Press, 1997. 222p.

PERDOMO, C.C. Alternativas para o manejo e tratamento de dejetos suínos. Suinocultura Indus., 23:16-26, 2001.

QUADROS, F.L.F. \& MARASCHIN, G.E. desempenho animal em misturas de espécies forrageiras de estação fria. Pesq. Agropec. Bras., 22:535-541, 1987.

REDOY, K.R.; KHALEEL, R.; OVERCASH, M.R. \& WESTERMAN, P.W. A moinpoint source model for land areas receiving animal wastes - I: Mineralization of organic nitrogen. Trans. Am. Soc. Agric. Eng., 22:63-872, 1979.
RESTLE, J.; ROSO, C.; SOARES, A.D.; LUPATINI, G.C.; ALVES FILHO, D.C. \& BRONDANI, I.L. Produtividade animal e retorno econômico em pastagem de aveia-preta mais azevém adubada com fontes de nitrogênio em cobertura. R. Bras. Zootec., 29:357-364, 2000.

ROWE, D.E. \& FAIRBROTHER, T.E. Harvesting winter forages to extract manure soil nutrients. Agron. J., 95:1209-1212, 2003.

SANDERSON, M.A.; JONES, R.M.; MCFARLAND, M.J.; STROUP, J.; REED, R.L. \& MUIR, J.P. Nutrient movement and removal in a Switchgrass biomass-filter strip system treated with dairy manure. J. Environ. Qual., 30:210-216, 2001.

SCHERER, E.E.; AITA, C. \& BALDISSERA, I.T. Avaliação da qualidade do esterco líquido de suínos da região Oeste Catarinense para fins de utilização como fertilizante. Florianópolis, EPAGRI, 1996. 46p. (Boletim Técnico).

TEDESCO, M.J.; GIANELLO, C.; BISSANI, C.A.; BOHNEN, H. \& VOLKWEISS, S.J. Análise de solo, plantas e outros materiais. 2.ed. Porto Alegre, Universidade Federal do Rio Grande do Sul, 1995. 174p.

TRENTIN, E.E.; BASSO, C.J.; CERRETA, C.A.; MOREIRA, I.L. \& GIROTTO, E. Produção de matéria seca e acúmulo de nitrogênio e fósforo com aplicação de esterco líquido de suínos na sucessão aveia-preta/milho/nabo forrageiro. In: REUNIÃO BRASILEIRA DE FERTILIDADE DO SOLO E NUTRIÇÃO DE PLANTAS - FERTIBIO, 15., Rio de Janeiro, 2002. Anais. Rio de Janeiro, Sociedade Brasileira de Ciência do Solo, 2002. CD-ROM.

WHALEN, J.K.; CHANG, C.; CLAYTON, G.W. \& CAREFOOT, J.P. Cattle manure amendments can increase the $\mathrm{pH}$ of acid soils. Soil Sci. Soc. Am. J., 64:962-966, 2000.

WHITEHEAD, D.C. Grassland nitrogen. Wallingford, CAB International, $1995.397 \mathrm{p}$.

WIETHÖLTER, S. Adubação nitrogenada no sistema plantio direto. Passo Fundo, Embrapa-CNPT, 1996. 44p.

ZEBARTH, B.J.; PAUL, J.W.; SCHMIDT, O. \& McDOUGAL, $R$. Influence of the time and rate of liquid manure application on yield and nitrogen utilization of silage corn in south coastal British Columbia. Can. J. Soil Sci., 76:153164,1996 